\title{
EVALUATION OF EATING ATTITUDES, ANGER AND IMPULSIVITY IN ATYPICAL AND NON-ATYPICAL DEPRESSION AND ASSESSMENT OF COMORBIDITY OF BINGE EATING
}

\author{
Buket Belkız Güngör ${ }^{1}$, Almıla İkra Akgül ${ }^{2}$, İbrahim Taymur ${ }^{2}$, Hakan Demirci ${ }^{3}$ \& Ahmet İnel $^{2}$ \\ ${ }^{I}$ Department of Psychiatry, Istanbul Bakırkoy Mental Health Training and Research Hospital, Istanbul, Turkey \\ ${ }^{2}$ Department of Psychiatry, Bursa Yuksek Ihtisas Training and Research Hospital, Bursa, Turkey \\ ${ }^{3}$ Department of Family Medicine, Bursa Yuksek Ihtisas Training and Research Hospital, Bursa, Turkey
}

received: 15.11.2018;

revised: 22.4.2019;

accepted: 16.12 .2019

\begin{abstract}
SUMMARY
Background: Although there have been studies investigating emotional eating, impulsivity and anger, the relationship between differentiated eating attitudes, impulsivity and anger in atypical depression has not yet been studied. Therefore, the aim of this study was to evaluate eating attitudes, impulsivity and anger in participants with atypical and non-atypical depression and to compare their behaviours with those of the control group. Binge eating comorbidity was also investigated. The relationship between eating attitudes, impulsivity and anger was explored and the factors contributing to disordered eating attitudes were analysed.

Subjects and methods: The participants were divided into three groups; 56 with atypical depression, 36 with non-atypical depression and 32 healthy controls for comparison. Clinical assessment was carried out using the Structured Clinical Interview for DSM-IV Axis I Disorders, Barratt Impulsiveness Scale, Multidimensional Anger Scale, Eating Attitude Test, and Hamilton Depression Scale.

Results: Deteriorated eating attitudes, increased anger symptoms and motor impulsivity were observed more in participants with atypical depression compared with participants with non-atypical depression. The frequency of binge eating was statistically significantly higher in participants with atypical depression (50\%) than in participants with non-atypical depression (8\%). A positive relationship was identified between deteriorated eating attitude, anger, and impulsivity. Behaving anxiously as a reaction to anger was found to be the significant predictor of disordered eating attitudes in participants with depression. The percentage of the variance explained by anxious behavior in disordered eating attitudes was $7 \%$.

Conclusion: Participants in the atypical and non-atypical depression groups can be differentiated from each other based on their eating attitudes, anger symptoms, motor impulsivity and binge eating frequency.
\end{abstract}

Key words: eating attitudes - anger - impulsivity - depression - binge eating

\section{INTRODUCTION}

DSM-IV-TR and DSM-5 provide a similar definition for atypical depressive disorder subtype. The primary characteristics of atypical depression are mood reactivity and vegetative symptoms. Weight gain and increased appetite are the primary dimensions of the vegetative symptoms along with a change in sleep duration. Few studies have reported particular features of atypical depression other than diagnostic criteria. Atypical depression has been diagnosed in $4.8 \%$ of clinical samples (Angst et al. 2002) and considered a chronic disorder characterised by female predominance, early onset and trait-like interpersonal sensitivity (Thase 2009). A previous study conceptualised atypical depression as a dimensional syndrome in which patients exhibit a variety of dysregulated emotional responses (Parker 2007).

\section{Depression and emotional eating}

Emotional eating is defined as eating in response to emotions. The relationship between negative emotions and increased eating behaviour has been investigated. If there is a belief or experience that some types of be- haviour induce positive state and decrease negative emotions, then they can be used to cope with depression (Ehring et al. 2010). Eating is defined as a strategy that can be used to regulate negative emotions; according to this strategy, eating can be converted and response to emotional rather than physical causes. Individuals who are depressed are found to be eating more. Strien suggested that emotional eating could be a marker for depression with atypical features (Van Strien et al. 2016).

\section{Emotional eating and impulsivity}

Factors contributing to emotional eating have been investigated in previous studies. Impulsivity, a character trait, increases during emotional eating (Bekker et al. 2004). Impulsive individuals may act rashly to alleviate negative affect. Bekker investigated the effect of negative affect induction and impulsivity on emotional eating in a healthy female population; results showed that individuals with higher impulsivity were more influenced by negative affect in emotional eating, and emotional eating increased when the negative affect was induced by an experimental procedure (Bekker et al. 2004). Impulsivity moderated the relationship between negative 
affect and increased calorie intake (Van Blyderveen et al. 2016). Gibson reported the relationship among emotional eating, depression and impulsivity; this study suggested genetic predisposition towards impulsivity, reward sensitivity and, as a consequence, a tendency to be depressive in emotional eating (Gibson 2012).

\section{Emotional eating and anger}

Anger, hostility and aggressiveness are personality traits that interact with impulsivity and predate eating pathology (Miottoa et al. 2008). Previous studies investigated the relationship between displaying anger and eating disorders. Women diagnosed with an eating disorder inhibited their expression of anger (Geller et al. 2000). Moreover, patients diagnosed with an eating disorder were unaware of and had difficulty in suitably expressing their anger and had turned the anger towards themselves (Thompson et al. 1999). Waller investigated the role of anger in a group of women with an eating disorder and found that they had higher levels of state anger and anger suppression (Waller et al. 2003). However, studies that investigated the relationship between anger and eating behaviour were almost entirely performed in participants with an eating disorder.

Although impulsivity and anger have been investigated in emotional eating and eating disorders, the relationship between differentiated eating attitudes, impulsivity and anger in atypical depression has not yet been studied. The present study asserts that long duration of atypical depression, inability to deal with negative emotions and character features can provoke maladaptive strategies. Eating behaviour is conceptualised as a maladaptive strategy to cope with depression, and this study investigated whether impulsivity and anger contribute to the presence of maladaptive eating behaviour. Considering impulsivity and anger as trait features, this work investigated whether impulsivity and anger in a group of participants with atypical depression differ from those in non-atypical depression and healthy control groups. The groups were compared according to the severity of depression and the number of suicide attempts. In addition, the groups were compared according to binge eating comorbidity. Binge eating disorder has been recognised as an eating disorder in DSM-5 and characterised by eating within a short period of time and a lack of control over eating. Binge eating was accompanied by affective lability, i.e. before binge eating, dysphoria was detected along with an anxiety component; during binge eating, the dysphoria decreased and the mood improved; and after the completion of binge eating, the dysphoria returned along with the depressive component (Greenberg \& Harvey 1987). Given that binge eating includes impulsive (Meule \& Platte 2015) and anger (Fassino et al. 2003) components, the atypical depressive groups that had and did not have binge eating comorbidity were compared to distinguish whether the differences in impulsivity and anger are responsible for binge eating comorbidity.

\section{SUBJECTS AND METHODS}

\section{Participants and procedures}

This study was conducted in the Outpatient Department of Psychiatry of Bursa Yuksek Ihtisas Training and Research Hospital between September 2013 and August 2014. Women aged between 18 and 50 years were included in this study. Since menopause is associated with several physiological changes, perimenopausal women were excluded from the study. In addition, participants having a physical or organic disease were excluded. The mean age of the atypical, nonatypical and control group was $32.84 \pm 9.26,31.08 \pm 8.97,31.56 \pm 6.05$ years, respectively. The participants had at least primary school education.

A total of 56 participants with atypical depression and 36 participants with non-atypical depression were recruited. Diagnosis of depression was confirmed by Structured Clinical Interview for DSM-IV (SCID-I) (First et al. 2002). The patients who had psychotic disorder, bipolar disorder, anxiety disorder, somatoform disorder, organic mental disorder, alcohol and substance use disorder except nicotine use disorder excluded due to possible confounding effects. SCID-I was administered and it was confirmed that there was no aforementioned psychiatric diagnosis other than depression. Symptoms of atypical depression subtype were evaluated according to DSM-5 definitions. The depressive participants were newly diagnosed and were not under any psychotropic therapy. The prevalence of each symptom in participants with atypical depression was as follows: increased appetite $(n=56$, $100 \%)$, hypersomnia $(n=38,67.9 \%)$, leaden paralysis $(n=54,96.4 \%)$ and rejection sensitivity $(n=47,83.9 \%)$. Patients with other mental and psychiatric disorders and depression with psychotic features were excluded from this study. Patients also never met the criteria for any other eating disorder except binge eating disorder. The diagnosis of eating disorder and binge eating disorder was defined according to the diagnostic criteria in DSM-5.

A total of 32 healthy control participants without any current or past mental disorder were recruited in this study. The control group was interviewed with SCID-I, and it was confirmed that there was no lifetime and current psychiatric diagnosis.

Participants were asked to self-report of their suicide attempts by face-to-face interviews. Barratt Impulsiveness Scale (BIS-11), Multidimensional Anger Inventory, Eating Attitude Test (EAT) and Hamilton Depression Scale (HAM-D) were administered to the participants. The severity of depression was assessed with HAM-D. Although, The EAT and the Eating Disorder Inventory-3 (EDI-3) are most widely used instruments in eating disorders, the EAT was used since the validation of EAT had been utilized (Savasir \& Erol 1989). However, EDI-3 which is a self-report questionnaire has not been validated. 
Written informed consent was obtained from all participants before enrolment, and the study was approved by the local ethics committee.

\section{Psychometric measures}

\section{Barratt Impulsiveness Scale (BIS-11)}

The BIS-11 is a 30 -item self-report questionnaire designed by Patton et al. to assess the trait impulsivity (Patton et al. 1995). Each item is rated on a 4-point Likert-type scale $(1=$ rarely/never and $4=$ almost always/always). BIS-11 consists of attentional, motor and non-planning subscales. Higher scores denote higher levels of impulsivity. Motor impulsiveness is considered as an indicator of behavioural impulsivity. Attentional impulsiveness and non-planning impulsiveness are considered as indicators of cognitive impulsiveness. The reliability and validity of BIS-11 in the context of Turkish version have been evaluated by Gulec et al. (2008).

\section{Multidimensional Anger Scale (MAS)}

This is a self-report scale developed by Balkaya and Sahin and was designed to assess anger on a multidimensional level (Balkaya \& Sahin 2003). It consists of the following five subscales: 'anger symptoms, anger-causing conditions, anger-related cognitions, anger reactions and interpersonal anger. Except anger symptoms, each dimension is composed of subscales. The total scores of anger-causing conditions and anger-related cognitions are calculated as the sum of the subscales. The anger-related behaviours dimension has three subscales, aggressive behaviours, calm behaviours and anxious behaviours. Some of the examples of the questions related to anxious behaviour when the participants felt angry were as follows: 'When I'm angry, I think I will lose my control' and 'When I'm angry, I think what I will do'.

The interpersonal anger dimension consists of the following four subscales: being revengeful, passiveaggressive reactions, inward-directed reactions and being neglectful. Each subscale is scored separately.

\section{The Eating Attitude Test (EAT-40)}

EAT was developed by Garner and Garfinkel (1979). It is a 40-item self-report scale designed to assess attitudes, behaviour and traits and has been used for the assessment of eating habits. The EAT has been adapted to Turkish settings (Savasır \& Erol 1989). The original form of EAT has the following four subscales: dieting behaviour, oral control, food preoccupation and body image. EAT subscales have not yet been assessed for validation in the Turkish version.

Hamilton Depression Scale (HAM-D): The original form prepared by Hamilton used to measure the severity of depression was a 17-item scale (Hamilton 1960). The HAM-D has been adapted to Turkish settings (Akdemir 1996).

\section{Statistical analysis}

Statistical analysis was carried out using SPSS 21.0. Descriptive statistics that were shown in Table 1 and 2 were reported to summarise the demographics of the groups. The categorical variables were expressed as frequency and percentages whereas continous variables were expressed as mean and standard deviation. Categorical data were analysed using the Chi-square test. The distribution of parameters for normality was assessed using Kolmogorov-Smirnov tests.

The Kruskal-Wallis test was used to compare continuous variables between participants with atypical depression and those with non-atypical depression and the control groups. The Mann-Whitney U test was used for specific group comparisons. The Bonferroni correction was applied for multiple comparisons between each pair of subgroups. There were three comparisions between three groups, therefore, $p$ value was divided by the number of comparisions. Differences were considered to be statistically significant when the $p$ values were $<0.0167(0.05 / 3)$.

The Mann-Whitney U test was also used to analyse the differences between participants with atypical depression with and without binge eating behaviour. Differences were considered to be statistically significant when the $p$ values were $<0.05$.

Correlations were evaluated by the Spearman correlation test.

Multiple linear regression analysis was carried out for further statistics to investigate explained variance between eating attitudes and anger and impulsivity. Significant factors that correlated with eating attitudes were included in the multiple linear regression analysis. Anger symptoms, anxious behaviour and attentional impulsivity were included in the model. The Backward method was utilised in the multiple regression analysis. The backward method started with fitting a model with anger symptoms, anxious behaviour and attentional impulsivity. The independent variables which did not contribute to the regression equation were deleted one by one until the remaning independent variable was statistically significant .

\section{RESULTS}

\section{Comparison between participants with atypical depression and non-atypical depression and the control group}

The three groups of women diagnosed with atypical depression $(n=56)$ and non-atypical depression $(n=36)$ and the healthy control group $(\mathrm{n}=32)$ were compared, and the major sociodemographic and clinical features of the study groups are presented in Table 1. There were no statistically significant differences among the groups in the demographic data, including age, education and marital status. 
Table 1. Comparision of demografic, clinical features and impulsivity, anger, eating attitudes between atypical depression, non-atypical depression and control group

\begin{tabular}{|c|c|c|c|c|c|c|c|}
\hline & $\begin{array}{l}\text { (1) Atypical } \\
\text { depression } \\
\mathrm{N}=56 \\
\text { Mean }(\mathrm{SD}) / \mathrm{n}\end{array}$ & $\begin{array}{c}\text { (2) Non-atypical } \\
\text { depression } \\
\mathrm{N}=36 \\
\text { Mean }(\mathrm{SD}) / \mathrm{n} \\
\end{array}$ & $\begin{array}{c}\text { (3) Control } \\
\mathrm{N}=32 \\
\text { Mean (SD)/n }\end{array}$ & F/Chi Square & $\begin{array}{c}1 \text { vs. } 2 \\
\text { p }\end{array}$ & $\begin{array}{c}1 \text { vs. } 3 \\
\text { p } \\
\end{array}$ & 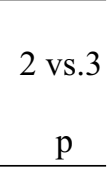 \\
\hline Age & $32.84 \pm 9.26$ & $31.08 \pm 8.97$ & $31.56 \pm 6.05$ & 0.529 & 0.270 & 0.979 & 0.343 \\
\hline Education & $8.38 \pm 3.01$ & $8.11 \pm 2.78$ & $9.34 \pm 1.47$ & 2.075 & 0.863 & 0.236 & 0.023 \\
\hline \multicolumn{8}{|l|}{ Marital status } \\
\hline $\begin{array}{l}\text { Married } \\
\text { Single (Divorced, Widowed) }\end{array}$ & $\begin{array}{l}42(75 \%) \\
14(25 \%)\end{array}$ & $\begin{array}{l}24(67 \%) \\
12(33 \%)\end{array}$ & $\begin{array}{l}21(65 \%) \\
11(35 \%)\end{array}$ & 1.151 & 0.386 & 0.348 & 0.928 \\
\hline $\begin{array}{l}\text { Suicide attempt } \\
\text { Yes } \\
\text { No }\end{array}$ & $\begin{array}{l}15(27 \%) \\
41(73 \%)\end{array}$ & $\begin{array}{c}7(19 \%) \\
29(81 \%)\end{array}$ & $\begin{array}{c}0(0 \%) \\
32(100 \%)\end{array}$ & 10.112 & 0.420 & 0.001 & 0.008 \\
\hline $\begin{array}{l}\text { Binge Eating } \\
\text { Yes } \\
\text { No }\end{array}$ & $\begin{array}{l}28(50 \%) \\
28(50 \%)\end{array}$ & $\begin{array}{c}3(8 \%) \\
33(92 \%)\end{array}$ & $\begin{array}{c}1(3 \%) \\
31(97 \%)\end{array}$ & 31.458 & $<0.001$ & $<0.001$ & 0.362 \\
\hline $\begin{array}{l}\text { HAM-D } \\
\text { Duration of illness (month) }\end{array}$ & $\begin{array}{c}14.34 \pm 5.29 \\
28.79 \pm 45.81\end{array}$ & $\begin{array}{c}13.92 \pm 5.64 \\
32.17 \pm 43.76\end{array}$ & $0.50 \pm 1.16$ & 99.510 & $\begin{array}{l}0.537 \\
0.317\end{array}$ & $<0.001$ & $<0.001$ \\
\hline AS & $42.96 \pm 11.23$ & $35.92 \pm 11.09$ & $27.28 \pm 8.85$ & 22.39 & 0.006 & $<0.001$ & 0.002 \\
\hline $\mathrm{ACC}$ & $164.20 \pm 26.71$ & $150.72 \pm 33.90$ & $140.75 \pm 34.99$ & 6.03 & 0.051 & 0.002 & 0.228 \\
\hline $\mathrm{ARC}$ & $88.29 \pm 29.46$ & $78.33 \pm 25.84$ & $54.47 \pm 18.26$ & 17.39 & 0.091 & $<0.001$ & $<0.001$ \\
\hline $\mathrm{AB}$ & $30.59 \pm 11.13$ & $26.89 \pm 10.49$ & $20.56 \pm 4.83$ & 10.87 & 0.102 & 0.392 & 0.010 \\
\hline $\mathrm{CB}$ & $31.96 \pm 9.25$ & $33.56 \pm 7.50$ & $29.91 \pm 7.00$ & 1.66 & 0.304 & $<0.001$ & 0.059 \\
\hline AnxB & $14.77 \pm 4.18$ & $13.78 \pm 3.70$ & $10.44 \pm 2.61$ & 14.26 & 0.125 & $<0.001$ & $<0.001$ \\
\hline $\mathrm{BR}$ & $65.00 \pm 23.62$ & $56.61 \pm 23.81$ & $46.41 \pm 19.10$ & 6.95 & 0.094 & $<0.001$ & 0.071 \\
\hline PAR & $32.61 \pm 8.61$ & $32.25 \pm 9.48$ & $28.31 \pm 7.55$ & 2.77 & 0.734 & 0.023 & 0.113 \\
\hline IDR & $34.29 \pm 7.60$ & $34.11 \pm 8.67$ & $27.59 \pm 6.96$ & 8.61 & 0.939 & $<0.001$ & 0.001 \\
\hline $\mathrm{BN}$ & $7.18 \pm 3.15$ & $6.97 \pm 2.80$ & $8.16 \pm 3.04$ & 1.50 & 0.738 & 0.171 & 0.084 \\
\hline EAT & $24.71 \pm 10.28$ & $17.11 \pm 8.14$ & $15.31 \pm 7.40$ & 13.81 & $<0.001$ & $<0.001$ & 0.313 \\
\hline AI & $17.32 \pm 3.40$ & $16.56 \pm 2.78$ & $13.31 \pm 3.18$ & 16.80 & 0.254 & $<0.001$ & $<0.001$ \\
\hline MI & $22.75 \pm 5.19$ & $19,92 \pm 3,95$ & $16.75 \pm 3.37$ & 17.71 & 0.016 & $<0.001$ & $<0.001$ \\
\hline NP & $28.52 \pm \pm 5.00$ & $26.53 \pm 4.71$ & $23.03 \pm 4.26$ & 13.62 & 0.056 & $<0.001$ & 0.003 \\
\hline
\end{tabular}

HAM-D - Hamilton Depression Scale; AS - Anger Symptoms; ACC - Anger Causing Conditions; ARC - Anger Related Cognitions; AR - Aggressive Behaviours; CB - Calm Behaviours; AnxB - Anxious Behaviours; BR - Being Revengeful;

PAR - Passive Aggressive Reactions; IDR - Inwards Directed Reactions; BN - Being Neglectful; EAT - Eating Attitudes Test;

AI - Attention Impulsivity; MI - Motor Impulsivity; NP - Non Planning

The duration of illness was similar between atypical and non-atypical depression groups. The frequency of binge eating was statistically significantly higher in participants with atypical depression (50\%) than that in participants with non-atypical depression $(8 \%)(\mathrm{p}<0.001)$. The frequency of suicide attempts and the HAM-D scores for participants with atypical depression and those with nonatypical depression were similar. Patients with atypical depression had more 'anger symptoms' and higher total EAT and higher motor impulsivity scores than those of participants with non-atypical depression.

\section{Comparison between participants with atypical depression with and without binge eating}

Based on the initial findings, we conducted further analyses for a comparison of the participants with atypical depression with and without binge eating $(n=56)$, as shown in Table 2. No difference, except for EAT scores, was observed between the groups.

\section{Correlations between EAT, HAM-D, anger and impulsivity}

Table 3 presents the correlations between EAT, HAM-D, anger and impulsivity. As shown in the table, a positive relationship was observed between EAT, anger symptoms and anxious behaviour, which is a subscale of anger-related behaviour and attentional impulsivity in participants with depression. Although the strength of the correlation seem weak, the analysis was statistically significant.

There was no significant correlation between EAT, anger and impulsivity in the healthy control group. The values of the pearson correlation coefficient between EAT and AS $(0.23, p=0.20), \operatorname{ACC}(0.08, p=063), \operatorname{ARC}$ (0.18, $\mathrm{p}=0.32), \mathrm{AB}(0.09, \mathrm{p}=0.60), \mathrm{CB}(-0.06, \mathrm{p}=0.70)$, AnxB (0.01, p=0.91), BR (0.17, p=0.34), PAR (0.02, $\mathrm{p}=0.89), \operatorname{IDR}(0.17, \mathrm{p}=0.34), \mathrm{BN}(0.008, \mathrm{p}=0.96), \mathrm{AI}$ $(0.20, p=0.25)$, MI $(0.12, p=0.50)$, NP $(-0.14, p=0.44)$ are presented. 
Table 2. Comparision of demografic, clinical features and impulsivity, anger, eating attitudes between atypical depression without and with binge eating groups

\begin{tabular}{|c|c|c|c|c|}
\hline & $\begin{array}{c}\text { Atypical depression } \\
\text { without binge eating } \\
n=28 \\
\text { Mean }(\mathrm{SD}) / \mathrm{n}\end{array}$ & $\begin{array}{c}\text { Atypical depression } \\
\text { with binge eating } \\
n=28 \\
\text { Mean }(\mathrm{SD}) / \mathrm{n}\end{array}$ & Z/Chi Square & $\mathrm{p}$ \\
\hline$\overline{\text { Age }}$ & $34.82 \pm 10.34$ & $30.86 \pm 7.72$ & -1.231 & 0.218 \\
\hline Education & $7.75 \pm 2.95$ & $9.00 \pm 3.00$ & -1.636 & 0.101 \\
\hline \multicolumn{5}{|l|}{ Marital status } \\
\hline Married & $21(75 \%)$ & $21(75 \%)$ & 0.000 & 1.000 \\
\hline Single (Divorced, Widowed) & $7(25 \%)$ & $7(25 \%)$ & & \\
\hline \multicolumn{5}{|l|}{ Suicide attempt } \\
\hline Yes & $6(21 \%)$ & $9(32 \%)$ & 0.820 & 0.274 \\
\hline No & $22(78 \%)$ & $19(68 \%)$ & & \\
\hline HAM-D & $14.39 \pm 4.15$ & $14.29 \pm 6.31$ & -0.904 & 0.366 \\
\hline AS & $42.11 \pm 13.46$ & $43.82 \pm 8.62$ & -0.279 & 0.780 \\
\hline $\mathrm{ACC}$ & $160.46 \pm 32.10$ & $167.93 \pm 19.87$ & -0.041 & 0.967 \\
\hline ARC & $87.93 \pm 31.80$ & $88.64 \pm 27.51$ & -0.057 & 0.954 \\
\hline $\mathrm{AB}$ & $29.89 \pm 12.44$ & $31.29 \pm 9.82$ & -0.820 & 0.412 \\
\hline $\mathrm{CB}$ & $30.64 \pm 9.81$ & $33.29 \pm 8.63$ & -0.796 & 0.426 \\
\hline AnxB & $15.11 \pm 4.14$ & $14.43 \pm 4.28$ & -0.725 & 0.469 \\
\hline $\mathrm{BR}$ & $63.43 \pm 23.76$ & $66.57 \pm 23.80$ & -0.467 & 0.640 \\
\hline PAR & $32.18 \pm 8.66$ & $33.04 \pm 8.70$ & -0.197 & 0.844 \\
\hline IDR & $34.50 \pm 6.75$ & $34.07 \pm 8.49$ & -0.057 & 0.954 \\
\hline $\mathrm{BN}$ & $6.32 \pm 2.97$ & $8.04 \pm 3.14$ & -1.910 & 0.056 \\
\hline EAT & $21.46 \pm 9.27$ & $27.29 \pm 11.16$ & -2.198 & 0.028 \\
\hline AI & $17.32 \pm 3.57$ & $17.32 \pm 3.28$ & -0.107 & 0.915 \\
\hline MI & $22.39 \pm 5.40$ & $23.11 \pm 5.05$ & -0.675 & 0.554 \\
\hline NP & $29.43 \pm \pm 4.03$ & $27.61 \pm 5.75$ & -1.060 & 0.289 \\
\hline
\end{tabular}

HAM-D - Hamilton Depression Scale; AS - Anger Symptoms; ACC - Anger Causing Conditions; ARC - Anger Related Cognitions; AR - Aggressive Behaviours; CB - Calm Behaviours; AnxB - Anxious Behaviours; BR - Being Revengeful;

PAR - Passive Aggressive Reactions; IDR - Inwards Directed Reactions; BN - Being Neglectful; EAT - Eating Attitudes Test; AI - Attention Impulsivity; MI - Motor Impulsivity; NP - Non Planning

Table 3. Correlations between Eating Attitudes Test and clinical and trait features; HAM-D, anger, and impulsivity $(n=92)$

\begin{tabular}{|c|c|c|c|c|c|c|c|c|c|c|c|c|c|c|}
\hline & HAM-D & $\mathrm{AS}$ & $\mathrm{ACC}$ & ARC & $\mathrm{AB}$ & $\mathrm{CB}$ & AnxB & $\mathrm{BR}$ & PAR & IDR & $\mathrm{BN}$ & AI & MI & NP \\
\hline EAT & 0.005 & $0.22 *$ & 0.10 & 0.20 & 0.15 & 0.008 & $0.26^{*}$ & 0.13 & 0.02 & 0.01 & 0.02 & $0.20 *$ & 0.17 & -0.03 \\
\hline
\end{tabular}

\section{Backward Stepwise multiple linear regression analysis of predictors of disordered eating attitudes}

Table 4 presents backward stepwise multiple linear regression analysis of predictors of disordered eating attitudes. The independent variables (anger symptoms, anxious behaviour, attentional impulsivity) which were significantly correlated with disordered eating attitudes were added into the model. Then, anger symptoms and attentional impulsivity which did not contribute to the model were removed from the model one by one. The multiple linear regression analysis revealed that anxious behaviour, which is a subscale of anger-related behaviour, was a significant independent contributor to disordered eating attitudes $\left(\mathrm{R}=0.261, \mathrm{R}^{2}=0.07\right)$.

\section{DISCUSSION}

The findings of this study indicated that participants with atypical depression and those with non-atypical depression could be distinguished from each other based on the frequency of binge eating and the levels of anger and motor impulsivity. Although the strength of the correlation seemed weak, a statistically significant positive correlation was observed among eating attitudes, anger symptoms and anxious behaviour, which is a subscale of anger-related behaviour and attentional impulsivity in participants with depression. Behaving anxiously as a reaction of anger was an independent contributor to disordered eating attitudes. The percentage of the variance explained by anxious behaviour in disordered eating attitudes was $7 \%$. 
Table 4. Backward stepwise multiple linear regression analysis of predictors of disordered eating attitudes

\begin{tabular}{|c|c|c|c|c|c|}
\hline \multirow{2}{*}{ Independent variables } & \multicolumn{2}{|c|}{ Unstandardized coefficient } & \multicolumn{2}{|c|}{ Standardized coefficient } & \multirow{2}{*}{$P$-value } \\
\hline & $B$ & Std. Error & $\beta$ & $t$ & \\
\hline \multicolumn{6}{|l|}{ Model 1} \\
\hline (Constat) & 3.925 & 6.208 & & 0.632 & 0.529 \\
\hline Anger symptoms & 0.079 & 0.100 & 0.089 & 0.783 & 0.436 \\
\hline Attentional impulsivity & 0.439 & 0.355 & 0.136 & 1.234 & 0.220 \\
\hline Anxious behavior & 0.485 & 0.285 & 0.189 & 1.705 & 0.092 \\
\hline \multicolumn{6}{|l|}{ Model 2} \\
\hline (Constat) & 4.811 & 6.091 & & 0.790 & 0.432 \\
\hline Attentional impulsivity & 0.515 & 0.341 & 0.216 & 1.510 & 0.135 \\
\hline Anxious behavior & 0.553 & 0.270 & 0.159 & 2.047 & 0.044 \\
\hline \multicolumn{6}{|l|}{ Model 3} \\
\hline (Constant) & 11.914 & 3.895 & & 3.058 & 0.003 \\
\hline Anxious behavior & 0.669 & 0.261 & 0.261 & 2.563 & 0.012 \\
\hline
\end{tabular}

Dependent variable: Eating attitudes; Model 1: $\mathrm{R}=0.312, \mathrm{R}^{2}=0.10 ;$ Model 2: $\mathrm{R}=0.302, \mathrm{R}^{2}=0.09 ;$ Model 3: $\mathrm{R}=0.261, \mathrm{R}^{2}=0.07$

\section{Presence of comorbid binge eating disorder in atypical depression}

In our study, binge eating was detected in $50 \%$ of participants with atypical depression. Our results are consistent with the study of Benazzi, who reported that $27 \%$ of participants with atypical depression and $10 \%$ with non-atypical depression had binge eating disorder (Benazzi 1999). Emotional eating has been suggested to be an antecedent in the development of binge eating (Stice 2002). A high rate of comorbidity has been frequently reported between atypical depression and binge eating (Angst et al. 2002). In the present study, no difference was found between participants with atypical depression with binge eating and those without binge eating, except for EAT scores (Table 2). Deterioration of eating attitudes was prominent in participants with atypical depression and binge eating. Participants diagnosed with atypical depression without binge eating had similar impulsivity and anger levels as those of participants with atypical depression with binge eating (Table 2). Increased impulsivity and anger appeared to be present independently from binge eating comorbidity in participants with atypical depression.

Despite the same psychiatric diagnosis, individuals who had increased levels of anger and impulsivity were found to have an increased rate of suicide attempts (Mann et al. 1999). Although we found that certain dimensions of anger and impulsivity were higher in participants with atypical depression than those in the non-atypical depression group, the rate of suicide attempts was similar between the two groups. Consistent with similar suicide rates, the severity of depression were similar between the groups.

\section{Impulsivity and disordered eating in atypical depression}

Motor impulsivity was higher in participants with atypical depression than that in participants with nonatypical depression (Table 1). Motor impulsivity is relevant to the inhibition of motor behaviour. Spence and Compasson reported that participants who behaviourally alleviated their negative mood were more likely to tent to do something and initiate eating behaviour as a coping mechanism (Spence \& Courbasson 2005). We speculated that inability to regulate negative emotions or cope with depression accompanied by motor impulsivity can result in compensatory behaviours, and eating behaviour could be one of the compensatory actions. Motor impulsivity can influence the initiation of maladaptive strategy by a behavioural response. In contrast to this view, a previous study suggested that depression and impulsivity were associated with emotional instability and that eating symptoms were characterised apart from these symptoms (Vaz-Leal et al. 2014). Although atypical and nonatypical depression could be distinguished from each other according to motor impulsivity, disordered eating attitudes showed significant positive correlation with attentional impulsivity in participants with depression (Table 3). Although a significant correlation was found for attentional impulsivity, the regression analysis did not confirm any significant effect of impulsivity on eating attitudes. This lack of detection of effect could be due to the small sample size. Disinhibition involves attentional impulsivity and motor impulsivity. Deficits in attentional and motor impulsivity have been suggested to be associated with the loss of control over eating (Lyke \& Spinella 2014). The inability for response inhibition to food cues and negative urgency (the tendency to behave rashly when emotionally distressed), which is one of the dimensions of affect-driven impulsivity, was associated with eating pathology (Whiteside \& Lynam 2001). Urgency was found to be associated with attentional impulsivity (Whiteside \& Lynam 2001). Another disordered eating, known as external eating, is defined as overeating in the presence of food-related cues, such as sight and smell of food. Hou suggested the link between attentional bias towards food cues and impulsivity in external eating 
(Hou et al. 2011). External eaters could also increase their food intake when they were under stress and negative affect. Moreover, depression could act as an indirect contributor to external eating by impulse dysregulation (Ouwens et al. 2009). Konttinen suggested that depression was associated with emotional and external eating (Konttinen et al. 2010).

\section{Comparison of impulsivity between atypical and non-atypical depression}

In the present study, participants with non-atypical depression were more impulsive than the control group and those with atypical depression were more impulsive than participants with non-atypical depression. In line with our results, Chopra reported that participants with atypical depression had significantly higher impulsivity than participants with non-atypical depression (Chopra et al. 2005). Several studies reported the relationship between impulsivity and depression and indicated impulsivity as a predictor of depression (Grano et al. 2007), but a previous review did not identify any consistency in the association between depression and impulsivity (Saddichha \& Schuetz 2014). Scholars proposed that BIS measures impulsivity as a stable trait and that the clinical state affects the BIS performance (Corruble et al. 2003). It has been suggested that motor impulsivity increase in bipolar disorder, regardless of the affective state (Lejoyeux et al. 2002). Another study reported that motor impulsivity was correlated with mania scores, and non-planning impulsivity was correlated with bipolar disorder depressive episode scores (Swann et al. 2008). Impulsivity has been considered to be inherent in bipolar disorder (Swann et al. 2001). We speculate that atypical depression and bipolar disorder could be similar according to the level of impulsivity. Furthermore, the comorbidity rates of binge eating in participants with atypical depression appeared to be as high as the rates in participants with bipolar spectrum disorders. Bipolar disorder and binge eating comorbidity have been reported frequently (Mc Elroy et al. 2005). By contrast, a study found high hypomania scores in individuals diagnosed with binge eating (Amianto et al. 2011). A probable association exists between bipolar disorder and problematic eating, especially binge eating behaviour. Studies have shown the association between atypical depression and bipolarity. Perugi found that $72 \%$ of patients with atypical depression could be classified as bipolar II, and atypical depression was associated with soft subtypes of the bipolar spectrum. About $60 \%$ of patients were found to be cyclothymic or hyperthymic before the diagnosis of atypical depression (Perugi et al. 1998). We speculate that the increased impulsivity and anger levels found in the participants with atypical depression could be linked to cyclothymic and hyperthymic temperaments. On the other hand, Benazzi reported that atypical features were more frequent in bipolar disorder depressive episodes (Benazzi
2000). Affective lability and the accompanying impulsivity were important factors of disordered eating (Anestis et al. 2009). Both atypical depression and bipolar disorder may be present with affective lability, in bipolar disorder with mood swings and in atypical depression with mood reactivity.

\section{Anger and disordered eating in atypical depression}

Participants with atypical depression had higher anger scores than participants with non-atypical depression (Table 1). Our results are consistent with the study of Chopra, who found the same differences between atypical depression and non-atypical depression groups (Chopra et al. 2005). A positive correlation was found between dysfunctional eating attitudes and anger. A relationship was also found among differentiated eating attitudes, anger symptoms and anxious behaviour (Table 3). The results of our study are in agreement with those of a previous work, which indicated that eating is a way to cope with anger (Russell \& Shirk 1993). Macht suggested that in response to anger, participants consumed more food, with an increase in impulsive eating (Macht 1999). Anger predicts unhealthy eating attitudes (Batıün \& Utku 2006). Another study reported disturbed control of aggressive impulses and indirect anger in disinhibited eating behaviour, but direct anger was not determined (Izydorczyk \& Mazur 2012). Truglia reported the relationship between maladaptive eating behaviour and inhibited anger expression (Truglia et al. 2006).

\section{Emotional eating, impulsivity and anger}

In our study, the deterioration of eating attitudes was greater in participants with atypical depression than in participants with non-atypical depression. The differentiated eating attitudes were found to be associated with reward and motivation pathways and altered signalling pathways involved in stress and affective disorders (Schellekens et al. 2012). Rahe found that patients with atypical depression preferred more energy-dense and low-quality food, and this preference was associated with increased appetite (Rahe et al. 2015). However, Kottingen explained altered eating habits based on the effect of emotional eating (Konttinen et al. 2010). In the present study, participants with atypical depression and those with non-atypical depression can be distinguished from each other based on their motor impulsivity and anger symptoms. In addition to this finding, anger symptoms and anxious behaviour were found to be correlated with dysfunctional eating attitudes. Furthermore, anxious behaviour, which is one of the dimensions of anger-related behaviour, was found to be a significant predictor of disordered eating attitudes in participants with depression. Behaving anxiously as a reaction of anger contributed to disordered eating attitudes. This result 
confirms that anger and its associated factors are related to differentiated eating habits in depression; hence, altered eating in participants with depression can be conceptualised as emotional eating. However, anxious behaviour was a reaction to previous anger, and we did not assess anxiety using separate scales, which is one of the limitations of this study.

Whether differentiated eating attitudes in participants with atypical depression is a physiological change related to vegetative symptoms of depression or a behaviour linked to moderate negative emotions remains unclear. Additional studies are required to understand the conceptualisation of atypical depression as a multidimensional disorder and highlight the common underlying psychobiological mechanisms of atypical depression and bipolar disorder. Further research is needed to investigate the similarities and differences between participants with bipolar disorder depressive episode and those with atypical depression. Longitudinal follow-up studies can delineate whether character traits, neurobiological features, emotional dysregulation or all of these factors precede the onset of eating and affective symptom comorbidity. The present study included only female participants; as such, we could not compare impulsivity, anger and eating attitudes between male and female gender. Female participants were found to be more impaired in eating attitudes and manifested anger as an introverted and passive-aggressive (e.g. smoking) manner, whereas males manifested anger by an extrovert expression (Russell \& Shirk 1993). Female gender was suggested to be a mediation effect for emotional eating in atypical depression (Van Strien et al. 2016). Female preponderance was found in atypical depression (Thase 2009) and emotional eating (Van Strien et al. 2016). Further studies comprising both sexes are needed to investigate gender effect. In addition, all the data obtained in this study were self-reported, and the responses might have been under-reported. Recall bias may also exist. Therefore, additional research is needed to detect weight gain by measurement and altered eating behaviours experimentally. Further studies with a larger sample size must evaluate the different aspects of impulsivity to clarify the relationship among atypical depression, impulsivity and disordered eating. Although the strength of the correlation between disordered eating attitudes, anger and impulsivity was weak and the variance explained by anxious behaviour in disordered eating attitudes was $7 \%$, it has been considered an important result from the view point of disordered eating attitudes that have been thought to be a multidimensional problem and have not yet been sufficiently investigated. Despite these limitations, to our knowledge, the findings of the present study have important implications for understanding the role of impulsivity and anger in emotional eating between participants with atypical depression and those with non-atypical depression.

\section{CONCLUSION}

The findings of this study have important implications for exploring dysfunctional eating attitudes in participants with atypical depression and those with non-atypical depression. The atypical depression group of participants were more impulsive and had more anger symptoms than the non-atypical depression group. Differentiated eating attitudes showed a positive correlation with attentional impulsivity and anger. The data indicate that anger may moderate dysfunctional eating attitudes in depression. The atypical depression group had significantly higher rates of binge eating comorbidity than the non-atypical depression group.

\section{Acknowledgements: None.}

\section{Conflict of interest: None.}

\section{Contribution of individual authors:}

Buket Belkız Güngör: study design, data collection, first draft, statistical analysis, approval of the final version.

Almıla İkra Akgül \& Ahmet İnel: data collection, literature review, approval of the final version.

Ibrahim Taymur: statistical analysis, approval of the final version.

Hakan Demirci: study design, manuscript revision, approval of the final version.

\section{References}

1. Akdemir A: Reliability and validity of the Turkish Version of the Hamilton Depression Rating Scale. 3P Dergisi 1996; 4:251-9. (Turkish)

2. Amianto $F$, Lavagnino L, Leombruni P, Gastaldi F, Daga GA, Fassino S: Hypomania across the binge eating spectrum. A study on hypomanic symptoms in full criteria and sub-threshold binge eating subjects. J Affect Disord 2011; 133:580-3

3. Anestis MD, Peterson CB, Bardone-Cone AM, Klein MH, Mitchell JE, Crosby RD, Crow SJ, le Grange D, Joiner TE: Affective lability and impulsivity in a clinical sample of women with bulimia nervosa: the role of affect in severely dysregulated behavior. Int J Eat Disord 2009; 42:259-66

4. Angst J, Gamma A, Sellaro R, Zhang H, Merikangas K: Toward validation of atypical depression in the community: results of the Zurich cohort study. J Affect Disord 2002: 72:125-38

5. Balkaya F \& Şahin NH: Multidimensional Anger Scale. Turk J Psychiatry 2003; 14:192-202. (Turkish)

6. Battgün $A D \&$ Utku C: A Study On the Relationship Between Eating Attitudes and Anger. Turk J Psychol 2006; 21:65-78

7. Bekker MH, Van de Meerendonk C, Mollerus J: Effects of negative mood induction and impulsivity on self-perceived emotional eating. Int J Eat Disord 2004; 36:461-69 
8. Benazzi F: Prevalance of bipolar 2 disorder in atypical depression. Eur Arch Psychiatry Clin Neurosci 1999; 249:62-5

9. Benazzi F: Depression with DSM-VI atypical features: a marker for bipolar II disorder. Eur Arch Psychiatry Clin Neurosci 2000; 250:53-4

10. Chopra KK, Bagby RM, Dickens S, Kennedy SH, Ravindran A, Levitan RD: A dimensional approach to personality in atypical depression. Psychiatry Res 2005, 134:161-7

11. Corruble E, Benyamina A, Bayle F, Falissard B, Hardy P: Understanding impulsivity in severe depression? A psychometrical contribution. Prog Neuro-Psychopharmacol Biol Psychiatry 2003; 27:829-33

12. Diagnostic and Statistical Manual of Mental Disorders, 5th ed. American Psychiatric Publishing American Psychiatric Association, Arlington 2013; pp 804

13. Ehring T, Tuschen-Caffier B, Schnülle J, Fischer S, Gross $J J$ : Emotion regulation and vulnerability to depression: spontaneous versus instructed use of emotion suppression and reappraisal. Emotion 2010; 10:563-72

14. Fassino S, Leombruni P, Pierò A, Abbate-Daga G, Giacomo Rovera G: Mood, eating attitudes, and anger in obese women with and without Binge Eating Disorder. $J$ Psychosom Res 2003; 54:559-66

15. First MB, Sipitzer RL, Gibbon M, Williams BW: Structured Clinical Interview for DSM-IV-TR Axis I Disorders, Research Version, Patient Edition. (SCID-I) Biometrics Research. New York State Psychiatric Institute, New York, 2002

16. Garner DM \& Garfinkel PE: The Eating Attitudes Test: an index of the symptoms of anorexia nervosa. Psychol Medi 1979; 9:273-79

17. Geller J, Cockell SJ, Goldner EM: Inhibited expression of negative emotions and interpersonal orientation in anorexia nervosa. Int J Eat Disord 2000; 28:8-19

18. Gibson EL: The psychobiology of comfort eating: implications for neuropharmacological interventions. Behav Pharmacol 2012; 23:442-60

19. Gulec H, Tamam L, Gulec MY, Turhan M, Karakus G, Zengin M, Stanford MS: Psychometric properties of the Turkish version of the Barratt impulsiveness scale-11. Bull Clin Psychopharmacol 2008; 18:251-58. (Turkish)

20. Greenberg BR \& Harvey PD: Affective lability versus depression as determinants of binge eating. Addict Behav 1987; 12:357-61

21. Grano N, Keltikangas-Jarvinen L, Kouvonen A, Virtanen $M$, Elovainio M, Vahtera J, Kivimaki: Impulsivity as a predictor of newly diagnosed depression. Scand J Psychol 2007; 48:173-9

22. Hamilton M: A Rating Scale for Depression. J Neurol Neurosurg Psychiatry 1960; 23:56

23. Hou R, Mogg K, Bradley BP, Moss-Morris R, Peveler R, Roefs A: External eating, impulsivity and attentional bias to food cues. Appetite 2011; 56:424-7

24. Izydorczyk B \& Mazur K: Characteristics of aggressive behaviour in females suffering from psychogenic binge eating disorder (analysis of the author's own research). Arch Psychiatry Psychother 2012; 3:15-24

25. Konttinen H, Männistö S, Sarlio Lähteenkorva S, Silventoinen K, Haukkala A: Emotional eating, depressive symptoms and self-reported food consumption: A population-based study. Appetite 2010; 54:473-9
26. Lyke JA \& Spinella M: Associations among aspects of impulsivity and eating factors in a nonclinical sample. Int J Eat Disord 2004; 36:229-33

27. Lejoyeux M, Arbaretaz M, Mc Loughlin M, Ades J: Impulse control disorders and depression. The Journal of Nervous and Mental Disease 2002; 190:310-4

28. Macht M: Characteristics of eating in anger, fear, sadness, and joy. Appetite 1999; 33:129-39

29. Mann JJ, Waternaux C, Haas GL, Malone KM: Toward a clinical model of suicidal behavior in psychiatric patients. Am J Psychiatry 1999; 156:181-9

30. Mc Elroy SL, Kotwal R, Keck PE, Akiskal HS: Comorbidity of bipolar and eating disorders: distinct or related disorders with shared dysregulations? J Affect Disord 2005; 86:107-27

31. Meule A \& Platte P: Facets of impulsivity interactively predict body fat and binge eating in young women. Appetite 2015; 87:352-7

32. Miottoa P, Pollinia B, Restaneoa A, Favarettob G, Pretic A: Aggressiveness, anger, and hostility in eating disorders. Compr Psychiatry 2008; 49:364-73

33. Ouwens MA, Van Strien T, Van Leeuwe JFJ: Possible pathways between depression, emotional and external eating: A structural equation model. Appetite 2009; 53:245-8

34. Parker GB: Atypical depression: a valid subtype? J Clin Psychiatry 2007; 68:18-22

35. Patton JH, Stanford MS, Barratt ES: Factor structure of the Barratt impulsiveness scale. J Clin Psychol 1995; 51:768-74

36. Perugi G, Akiskal HS, Lattanzi L, Cecconi D, Mastrocinque C, Patronelli A, Vignoli S, Bemi E: The high prevelance of 'soft' bipolar II; features in atypical depression. Compr Psychiatry 1998; 39:63-71

37. Rahe C, Baune BT, Unrath M, Arolt V, Wellmann J, Wersching H, Berger K: Associations between depression subtypes, depression severity and diet quality: Crosssectional findings from the BiDirect study. BMC Psychiatry 2015; 15:1-9

38. Russell SS \& Shirk B: Women's anger and eating. Women and Anger 1993; 15:170-85

39. Saddichha S, Schuetz C: Impulsivity in remitted depression: A meta-analytical review. Asian J Psychiatry 2014; 9:13-6

40. Savasir I \& Erol N: Eating Attitudes Test: anorexia nervosa symptoms index. Psikoloji Dergisi 1989; 7:19-25. (Turkish)

41. Schellekens H, Finger BC, Dinan TG, Cryan JF: Ghrelin signalling and obesity: At the interface of stress, mood and food reward. Pharmacol Ther 2012; 135:316-26

42. Spence $S \&$ Courbasson $C$ : The role of emotional dysregulation in concurrent eating disorders and substance use disorders. Eat Behav 2012; 13:382-5

43. Stice E: Risk and maintenance factors for eating pathology: A meta-analytic review. Psychol Bull 2002; 128:825-48

44. Swann AC, Anderson JC, Dougherty DM, Moeller FG: Measurement of inter-episode impulsivity in bipolar disorder. Psychiatry Res 2001; 101:195-7

45. Swann AC, Steinberg JL, Lijffijt M, Moeller FG. Impulsivity: Differential relationship to depression and mania in bipolar disorder. J Affect Disord 2008; 106:241-8 
46. Thase ME: Atypical depression: useful concept, but it's time to revise the DSM-IV criteria. Neuropsychopharmacology 2009; 34:2633-41

47. Thompson KM, Wonderlich SA, Crosby RD, Mitchell JE: The neglect link between eating disturbances and aggressive behavior in girls. $\mathrm{J}$ Am Acad Child Adol Psychiatry 1999; 38:1277-84

48. Truglia E, Mannucci E, Lassi S, Rotella CM, Faravelli C, Ricca, V: Aggressiveness, anger and eating disorders: $A$ review. Psychopathology 2006; 39:55-68

49. Van Blyderveen $S$, Lafrance A, Emond M, Kosmerly $S$, $O^{\prime}$ Connor $M$, Chang $F$ : Personality differences in the susceptibility to stress-eating: The influence of emotional control and impulsivity. Eat Behav 2016; 23:76-81

50. Van Strien T, Winkens L, Toft MB, Pedersen S, Brouwer I, Visser M, Lahteenmaki L: The mediation effect of emotional eating between depression and body mass index in the two European countries Denmark and Spain. Appetite 2016; 105:500-8

51. Vaz-Leal FJ, Rodríguez-Santos L, García-Herráiz MA, Chimpén-López CA, Rojo-Moreno L, Beato-Fernández L, Ramos-Fuentes MI: The role of depression and impulsivity in the psychopathology of bulimia nervosa. Revista de Psiquiatria y Salud Mental 2014; 7:25-31

52. Waller $G$, Babbs $M$, Milligan $R$, Meyer $C$, Ohanian $V$, Leung $N$ : Anger and core beliefs in the eating disorders. Int J Eat Disord 2003; 34:118-24

53. Whiteside SP \& Lynam DR: The Five Factor Model and impulsivity: Using a structural model of personality to understand impulsivity. Personality and Individual Differences 2001; 30:669-89

Correspondence:

Buket Belkız Güngör, MD

Bakırköy Mental Health Training and Research Hospital, Psychiatry Department

Istanbul, Turkey

E-mail: buket.gungor@yahoo.com 